\section{$\leqslant$ Research Square}

Preprints are preliminary reports that have not undergone peer review. They should not be considered conclusive, used to inform clinical practice, or referenced by the media as validated information.

\title{
The Correlation Between Vitamin D at Birth and Growth at 6 Months of Age in Twins: from a Prospective Longitudinal Birth Cohort
}

Xin Li

The First Affiliated Hospital of Chongqing Medical University

Jiaxiao Yu

The First Affiliated Hospital of Chongqing Medical University

\section{Li Wen}

The First Affiliated Hospital of Chongqing Medical University

Jianying Yan

Fujian Provincial Maternity and Children's Hospital

Jing Tian

University-Town Hospital of Chongqing Medical University

Chao Tong ( $\sim$ chaotongcqmu@163.com )

The First Affiliated Hospital of Chongqing Medical University https://orcid.org/0000-0003-0828-2674

Qi Tong

Chongqing Population and Family Planning Research Institute

Hongbo Qi

The First Affiliated Hospital of Chongqing Medical University

Richard Saffery

Murdoch Childrens Research Institute

Mark D. Kilby

University of Birmingham Edgbaston campus: University of Birmingham

Philip N. Baker

University of Leicester College of Life Sciences

\section{Research article}

Keywords: vitamin D, twin pregnancies, neonates, prospective study, nutrition

Posted Date: November 13th, 2020

DOI: https://doi.org/10.21203/rs.3.rs-105080/v1 
License: (c) (i) This work is licensed under a Creative Commons Attribution 4.0 International License. Read Full License

Version of Record: A version of this preprint was published at BMC Pregnancy and Childbirth on April 8th, 2021. See the published version at https://doi.org/10.1186/s12884-021-03707-7. 


\section{Abstract}

Background: Vitamin D deficiency is a global public health issue in women and children, is associated with adverse impacts on child growth, such as rickets. However, prior studies have mainly focused on measuring vitamin $D$ levels in singleton pregnant women and their offspring, very limited studies have revealed the prevalence of vitamin $D$ deficiency in twin pregnant women and their offspring. The aim of this study was to investigate vitamin D levels in twin pregnant women and their neonates. We also explored the correlation of maternal vitamin D levels with neonatal outcomes and infant growth.

Methods: A prospective subcohort investigation was carried out among 72 dichorionic twin pregnant mothers and their twin offspring from the Longitudinal Twin Study. Peripheral blood was collected from the mothers in the third trimester and cord blood was collected form neonates at birth to identify 25[OH]D levels. Data on the characteristics of the mothers and neonates were collected. Infant growth data and food sensitivities were also collected.

Results: The average maternal 25[OH]D level was $31.78 \mathrm{ng} / \mathrm{mL}$, with $19.4 \%$ being deficiency and $20.8 \%$ insufficiency, while the average neonatal 25[OH]D level was $15.37 \mathrm{ng} / \mathrm{mL}$, with $99.3 \%$ being deficiency or insufficiency. A positive correlation was found between maternal and neonatal 25[OH]D levels (betavalue: $0.43,95 \% \mathrm{Cl}: 0.37,0.49)$. Interestingly, the higher the maternal $25[\mathrm{OH}] \mathrm{D}$ level was, the smaller the co-twins birthweight discordance (beta-value: $-2.67,95 \% \mathrm{Cl}$ : $-5.11,-0.23$ ). In addition, the infants of mothers with vitamin $D$ deficiency were more likely to be allergic to foods at six months than those of mothers with vitamin D sufficiency.

Conclusions: Twin neonates were at extremely high risk of vitamin D deficiency although their mothers' vitamin D deficiency partially improved. Higher maternal vitamin D level was associated with smaller discordance of co-twins birthweight.

\section{Trial registration: ChiCTR-OOC-16008203}

\section{Background}

Vitamin $\mathrm{D}$ is a potent steroid hormone that is not only essential for building and maintaining bones but also plays an important role in the immune, endocrine and cardiovascular systems [1-4]. Although both animal-derived and plant-derived food sources can provide some vitamin $D$, the main source of vitamin $D$ in the body depends on exposure to sunlight $[5,6]$. However, the amount of time that people spend in the sun in modern society is not enough to meet their vitamin D needs [7, 8], especially since excessive ultraviolet radiation causes skin problems. In addition, ethnicity, latitude and body mass index also influence vitamin D status [9-11].

Vitamin D deficiency is a global public-health problem, especially among pregnant women and newborns $[12,13]$. A deficiency of vitamin $D$ in pregnant women increases the risk of gestational diabetes, gestational hypertension disorder and insufficient gestational weight gain and may affect fetal growth 
and bone ossification $[14,15]$. cs with a vitamin D deficiency have been shown to have a higher risk of calcemia and respiratory distress syndrome, and a higher likelihood of developing food sensitivities, asthma, type I diabetes or autism in their later life [16-20]. Previous studies have revealed that vitamin D status in the fetus and newborn is largely dependent on maternal vitamin D status, thus, the main risk factor for newborn vitamin D deficiency is maternal vitamin D deficiency [21-23]. However, the data on vitamin $\mathrm{D}$ status among twin pregnant women and their offspring are very limited.

In recent decades, the prevalence of twin pregnancies has increased 1.8 fold according to the National Vital Statistics Report of the US due to the development of assisted reproductive technology and advanced maternal age [24-26]. In comparison with those with singleton pregnancy, women who are pregnant with twins are considered to undergo more complex physiological changes and obviously have a higher risk of adverse obstetric consequences $[27,28]$. More attention should be paid to twin pregnancies with respect to nutrition and vitamin supplementation. Thus, it is essential to clarify whether vitamin $\mathrm{D}$ deficiency in mothers and newborns worsens among twin pregnancies.

Therefore, in the present study, we aimed to investigate the status of $25[\mathrm{OH}] \mathrm{D}$ in mothers and their newborns in a twin pregnancies and birth cohort from Southwest China. Given the previous findings reported for singleton pregnancy, we also aimed to determine the impact of maternal 25[OH]D deficiency on maternal and neonatal outcomes as well as child growth.

\section{Methods}

\section{Study design and participants}

The present study was embedded in the Longitudinal Twin Study (LoTiS), an ongoing twin pregnancies and birth cohort study conducted in Chongqing. Chongqing is situated in southwestern China at latitude of $29.35^{\circ} \mathrm{N}$ and characterized by a subtropical monsoon humid climate. This city has insufficient sunshine (1000-1400 h/year), especially in winter and spring. The LoTiS twin cohort study was established in January 2016 and aims to unravel the complex interplay between genes and the environment in specifying early life determinants of illness in infancy (Chinese Clinical Trial Registration Number:ChiCTR-OOC-16008203) and was approved by the Ethics Committee of the First Affiliated Hospital of Chongqing Medical University (No. 201530). Written informed consent was obtained from all participants. This subgroup study included dichorionic twin pregnant women with a prepregnancy BMI in the normal range (18.5 23.9) as well as daily multivitamin (vitamin D: 500IU) supplementation from the first trimester to delivery. Mothers with chronic metabolic diseases and those using immunosuppressants were excluded. Twin pairs with a birth weight $<1500 \mathrm{~g}$, significant malformations, or genetic disorders were also excluded. All twin offspring received daily usage of vitamin D supplements ( $400 \mathrm{lU} /$ day) from birth, and had a pediatric follow-up visit thereafter at a corrected age of 6 months.

\section{Data collection}


Maternal sociodemographic data (age, height, weight, education, occupation, parity, mode of conception), lifestyle behaviors before pregnancy (smoking and alcohol use) and pre-existing conditions were collected by standardized questionnaire in the first follow-up during 11-16 gestational weeks. The standardized questionnaire was self-designed for LoTiS cohort study, and detailed information was presented in Supplementary File 1. Information about vitamin D supplementation and other nutrients was collected using a structured questionnaire during the third trimester. The detailed information of this questionnaire is presented in Supplementary File 2. Pregnancy complications, maternal and neonatal outcomes including gestational age, preterm premature rupture of membranes (PPROM, <37 gestational weeks), neonatal gender, birthweight and small-for-gestational age (SGA, defined as a weight below the 10th percentile for GA and sex [29]) were collected from medical records.

\section{Measurement of serum 25[OH]D and classification criteria}

Peripheral blood samples were collected from the mothers in the third trimester, and cord blood samples were immediately collected from newborns after placenta delivery by using a coagulation-promoting blood collection tube. The specimen was transported to the Maternal and Fetal Medical Laboratory under refrigeration, where they were centrifuged to obtain serum. There the serum $25[\mathrm{OH}] \mathrm{D}$ level was measured by high performance liquid chromatography-electrospray tandem mass spectrometry (HPLC-MS-MS, Waters, USA), which is the gold standard method [30]. The concentrations of $25[\mathrm{OH}] \mathrm{D}_{3}$ and $25[\mathrm{OH}] \mathrm{D}_{2}$ were measured separately, and the total level of $25[\mathrm{OH}] \mathrm{D}$ was the sum of $25[\mathrm{OH}] \mathrm{D}_{3}$ and $25[\mathrm{OH}] \mathrm{D}_{2}$.

Serum 25[OH]D is the best estimator to assess the body vitamin D levels in the body [31]. For analysis, we divided mothers into 3 groups based on 25[OH]D levels: 25[OH]D levels $<20 \mathrm{ng} / \mathrm{mL}$ indicated a deficiency, $25[\mathrm{OH}] \mathrm{D}$ levels in the range of $20-30 \mathrm{ng} / \mathrm{mL}$ indicated an insufficiency, and 25[OH]D levels $>30 \mathrm{ng} / \mathrm{mL}$ were considered sufficiently high [32]. The same cut-offs were used for neonates according to the Chinese standard [33].

\section{Infant growth assessment and skin prick test}

Infants growth was monitored for weight and length at the corrected age of 6 months. The corrected age was defined as the infant's chronological age minus the difference between term birth (40 weeks) and chronological gestational weeks of delivery. Weight and length were simultaneously measured unclothed by a digital measuring bed (Beideneng, Shanghai, China) operated by trained nurses at the Department of Child Health Care of Chongqing Health Center for Women and Children. The indexes of weight, height and BMI were converted to Z-scores for sex and age according to the WHO Child Growth Standards software (https://www. who. int/childgrowth/software/en/).

On the same day, a skin prick test (SPT) was performed to preliminarily diagnose food allergies. The SPT was performed on the volar surface of the forearm with a lancet through the use of a drop of an allergen extract and test results were produced in 15 to $20 \mathrm{~min}$. The routine test screened for food types including milk, egg white, egg yolk, peanut, fish, wheat, soybean, citrus, and apple. 


\section{Statistical methods}

All statistical analyses were performed with SPSS version 25.0 (IBM, Armonk, NY, USA). Categorical variables are presented as the count and percentage, and were analyzed by the Chi-squared or Fisher's exact test. Continuous variables are presented as means and standard deviation, and were analyzed by Student's t-test, LSD student's t test, one-way analysis of variance or the nonparametric test. Linear correlation analysis was used to explore the correlation between $25[\mathrm{OH}] \mathrm{D}$ levels in mothers and newborns and the correlation of 25[OH]D levels between co-twins. Multivariable linear regression analysis was used to detect the associations between neonatal 25[OH]D levels and related clinical characteristics. All tests were two-tailed and $p<0.05$ was considered statistically significant.

\section{Results}

The selection process for this study population is presented in Fig. 1. A total of 190 dichorionic twin pregnancies from LoTiS were initially recruited into this subgroup study. After excluding mother-twin offspring pairs that did not meet the inclusion criteria and did not have blood samples, a total of 72 mother-twin offspring pairs were available for the final analysis. The descriptive data of the study participants are shown in Table 1. The average maternal age at recruitment was $30.46 \pm 2.93$ years, and the average gestational age was $36.77 \pm 1.16$ weeks. The mean birth weight of all neonates was 2626.53 $\pm 329.96 \mathrm{~g}$. In addition, $62.5 \%$ of mothers conceived with the aid of assisted reproductive technology (ART), and $66.7 \%$ of mothers delivered in the summer or autumn. The average maternal 25[OH]D level was $31.78 \pm 11.1 \mathrm{ng} / \mathrm{mL}$, with $19.5 \%$ of mothers being deficiency and $20.8 \%$ being insufficiency. Unexpectedly, the average neonatal 25[OH]D level was $15.37 \pm 4.86 \mathrm{ng} / \mathrm{mL}$, with $78.5 \%$ of neonates being deficiency and $20.8 \%$ being insufficiency. 
Table 1

Description of the maternal and neonatal characteristics.

\begin{tabular}{|ll|}
\hline Variables & Total \\
\hline Mothers & 72 \\
\hline Age (year) & $30.46 \pm 2.93$ \\
\hline Pre-pregnancy BMI $(\mathrm{kg} / \mathrm{m} 2)$ & $21.15 \pm 1.32$ \\
\hline Mode of conception & \\
\hline Natural conception & $27(37.5 \%)$ \\
\hline Assisted reproductive technology & $45(62.5 \%)$ \\
\hline Gestational weight gain $(\mathrm{kg})$ & $17.65 \pm 5.89$ \\
\hline Gestational age $(\mathrm{week})$ & $36.77 \pm 1.16$ \\
\hline Preterm birth & $33(45.8 \%)$ \\
\hline Sampling season & \\
\hline Summer/autumn & $24(33.3 \%)$ \\
\hline Winter/spring & $48(66.7 \%)$ \\
\hline $25[O H] D$ level $(\mathrm{ng} / \mathrm{mL})$ & $31.78 \pm 11.1$ \\
\hline Deficiency $(<20 \mathrm{ng} / \mathrm{mL})$ & $14(19.5 \%)$ \\
\hline Insufficiency $(20-30 \mathrm{ng} / \mathrm{mL})$ & $15(20.8 \%)$ \\
\hline Sufficiency $(>30 \mathrm{ng} / \mathrm{mL})$ & $43(59.7 \%)$ \\
\hline Infants & 144 \\
\hline Gender (male) & $70(48.6 \%)$ \\
\hline Birthweight (g) & $2626.53 \pm 329.96$ \\
\hline SGA & $5(3.5 \%)$ \\
\hline $25[0 H] D$ level (ng/mL) & $15.37 \pm 4.86$ \\
\hline Deficiency $(<20 \mathrm{ng} / \mathrm{mL})$ & $113(78.5 \%)$ \\
\hline Insufficiency $(20-30 \mathrm{ng} / \mathrm{mL})$ & $30.8 \%)$ \\
\hline Sufficiency $(>30 \mathrm{ng} / \mathrm{mL})$ & \\
\hline
\end{tabular}

In the maternal vitamin D deficiency group, over a half of the mothers conceived with ART and were complicated with gestational diabetes, and $78.6 \%$ delivered in the winter or spring; this group had the 
highest incidence of SGA, with the lowest birthweight as well as the highest birthweight discordance (Table 2). 
Table 2

Description of the maternal and neonatal characteristics by maternal vitamin D status.

\begin{tabular}{|c|c|c|c|c|}
\hline Variables & Deficiency & Insufficiency & Sufficiency & p-value \\
\hline Mothers & $N=14$ & $N=15$ & $N=43$ & \\
\hline Age (year) & $29.86 \pm 3.57$ & $29.87 \pm 3.54$ & $30.86 \pm 3.52$ & $0.394^{\mathrm{a}}$ \\
\hline Pre-pregnancy BMI (kg/m2) & $20.76 \pm 1.30$ & $20.50 \pm 1.26$ & $21.50 \pm 1.62$ & $0.054^{a}$ \\
\hline Mode of conception & & & & $0.868^{b}$ \\
\hline Natural conception & $6(42.9 \%)$ & $5(33.3 \%)$ & $16(37.2 \%)$ & \\
\hline ART & $8(57.1 \%)$ & $10(66.7 \%)$ & $27(62.8 \%)$ & \\
\hline Pregnancy weight gain $(\mathrm{kg})$ & $17.50 \pm 4.97$ & $19.43 \pm 4.44$ & $17.07 \pm 6.55$ & $0.412^{\mathrm{a}}$ \\
\hline Gestational age (week) & $36.62 \pm 0.97$ & $36.98 \pm 1.08$ & $36.73 \pm 1.24$ & $0.473^{\mathrm{a}}$ \\
\hline Preterm birth & $7(50.0 \%)$ & $6(40.0 \%)$ & $20(46.5 \%)$ & $0.856^{\mathrm{b}}$ \\
\hline \multicolumn{5}{|l|}{ Pregnancy-induced illness } \\
\hline GDM & $8(57.1 \%)$ & $6(40.0 \%)$ & $12(27.9 \%)$ & $0.133^{b}$ \\
\hline GHD & $1(7.1 \%)$ & $1(6.7 \%)$ & $2(4.7 \%)$ & $0.510^{c}$ \\
\hline ICP & $4(28.6 \%)$ & $0(0 \%)$ & $8(18.6 \%)$ & $0.919^{c}$ \\
\hline Sampling season & & & & $0.538^{\mathrm{b}}$ \\
\hline Summer/autumn & $3(21.4 \%)$ & $6(40.0 \%)$ & $15(34.9 \%)$ & \\
\hline Winter/spring & $11(78.6 \%)$ & $9(60.0 \%)$ & $28(65.1 \%)$ & \\
\hline Infants & $N=28$ & $N=30$ & $N=86$ & \\
\hline Gender (male) & $12(42.9 \%)$ & $19(63.3 \%)$ & $39(45.3 \%)$ & $0.188^{b}$ \\
\hline Birthweight (g) & $2453(365)$ & $2740(274)$ & $2641(347)$ & $0.001^{d}$ \\
\hline Birthweight discordance (\%) & $8.83(1.21)$ & $6.93(3.87)$ & $5.72(4.06)$ & $0.048^{d}$ \\
\hline SGA & $2(7.1 \%)$ & $1(3.3 \%)$ & $2(2.3 \%)$ & $0.481^{\mathrm{c}}$ \\
\hline $25[\mathrm{OH}] \mathrm{D}$ level $(\mathrm{ng} / \mathrm{mL})$ & $7.93(6.20)$ & $12.89(6.34)$ & $18.75(5.46)$ & $<0.001^{d}$ \\
\hline
\end{tabular}


BMI, body mass index; ART, assisted reproductive technology; GDM, gestational diabetes; GHD, gestational hypertension disorder; ICP, intrahepatic cholestasis of pregnancy; SGA, small for gestational age.

a Average and standard deviation. One-way Analysis of Variance

b Number (percentage). Chi-squared Test

c Number (percentage). Fisher Exact Test

d Median (interquartile range). Kruskal-Wallis Test

A significant difference in neonatal 25[OH]D levels was found among the maternal vitamin D deficiency, insufficiency and sufficiency groups (Table 2). There was a directly proportional correlation between maternal 25[OH]D levels and neonatal 25[OH]D levels $(r=0.90, p<0.001)$ (Fig. 2A). In addition, a significantly positive correlation was found between co-twins in terms of neonatal 25[OH]D level $(r=0.91$, $\mathrm{p}<0.001$ ) (Fig. 2B). Multivariable linear regression showed that neonatal 25[OH]D levels were only positively associated with maternal $25[\mathrm{OH}] \mathrm{D}$ levels (beta-value: $0.43,95 \% \mathrm{Cl}: 0.37,0.49 . p<0.001$ ) and were not found to have a correlation with maternal age, BMI, gestational weight gain, gestational age, birth season or neonatal birthweight (Table 3).

Table 3

Association between continuous characteristics and neonatal 25[OH]D levels.

\begin{tabular}{|llll|}
\hline Variables & Beta & $95 \%$ Cl & P-value \\
\hline Maternal 25[OH]D level & 0.43 & $(0.37,0.49)$ & $<0.001$ \\
\hline Maternal age & 0.05 & $(-0.13,0.22)$ & 0.589 \\
\hline Maternal prepregnancy BMI & -0.01 & $(-0.45,0.43)$ & 0.976 \\
\hline Maternal gestational weight gain & -0.02 & $(-0.14,0.10)$ & 0.725 \\
\hline Gestational age at delivery & -0.56 & $(-1.22,0.10)$ & 0.093 \\
\hline Birth season & -1.04 & $(-2.39,0.31)$ & 0.129 \\
\hline Neonatal birth weight & 1.45 & $(-1.05,3.95)$ & 0.252 \\
\hline
\end{tabular}

The neonatal birthweight and the discordance in birthweight between co-twins were significantly different between the maternal 25[OH]D deficiency and sufficiency groups (Fig. 3A-C). After adjusting for maternal age, $\mathrm{BMI}$, gestational weight gain, gestational age and birth season, the results suggested that there was no correlation between maternal 25[OH]D levels and neonatal birthweight (Table 4). Surprisingly, maternal $25[\mathrm{OH}] \mathrm{D}$ levels were negatively correlated with the discordance in birthweight between co-twins, with the 
discordance in birthweight between co-twins decreased 2.67\% when maternal 25[OH]D level increased by $1 \mathrm{ng} / \mathrm{mL}(95 \% \mathrm{Cl}:-5.11,-0.23 . p=0.032)$ (Fig. 3C).

Table 4

Association between continuous characteristics and neonatal birthweight.

\begin{tabular}{|llll|}
\hline Variables & Beta & $95 \% \mathrm{Cl}$ & P-value \\
\hline Maternal 25[OH]D level & 0.01 & $(-0.01,0.01)$ & 0.513 \\
\hline Maternal age (years) & 0.01 & $(-0.01,0.02)$ & 0.806 \\
\hline Maternal prepregnancy BMI & 0.06 & $(0.03,0.09)$ & 0.019 \\
\hline Maternal gestational weight gain & 0.01 & $(0.01,0.03)$ & 0.014 \\
\hline Gestational age at delivery & 0.15 & $(0.11,0.19)$ & $<0.001$ \\
\hline Birth season & 0.11 & $(0.02,0.20)$ & 0.013 \\
\hline
\end{tabular}

At six months of corrected age, the z-scores of the weight-for-age, height-for-age, weight-for-height, and BMI-for-age indexes showed no differences among the maternal 25[OH]D deficiency, insufficiency and sufficiency groups for all infants taking vitamin D supplements each day. However, in the maternal vitamin $\mathrm{D}$ deficiency group, the incidence of allergies to foods was highest (Table 5).

Table 5

Description of the growth and food sensitivity by maternal 25[OH]D status

\begin{tabular}{|c|c|c|c|c|}
\hline Variables & $\begin{array}{l}\text { Deficiency } \\
(\mathrm{N}=28)\end{array}$ & $\begin{array}{l}\text { Insufficiency } \\
(\mathrm{N}=30)\end{array}$ & $\begin{array}{l}\text { Sufficiency } \\
(\mathrm{N}=86)\end{array}$ & p-value \\
\hline WHZ & $0.39 \pm 0.80$ & $0.47 \pm 0.73$ & $0.35 \pm 0.82$ & $0.828^{a}$ \\
\hline WAZ & $0.41 \pm 0.88$ & $0.59 \pm 0.97$ & $0.34 \pm 0.85$ & $0.527^{a}$ \\
\hline HAZ & $0.29 \pm 1.10$ & $0.57 \pm 1.21$ & $0.42 \pm 0.95$ & $0.673^{a}$ \\
\hline BAZ & $0.34 \pm 0.66$ & $0.38 \pm 0.98$ & $0.36 \pm 0.79$ & $0.981^{\mathrm{a}}$ \\
\hline Allergic to one or more food & $4(14.3 \%)$ & $2(6.7 \%)$ & $4(4.7 \%)$ & $0.200^{b}$ \\
\hline \multicolumn{5}{|c|}{$\begin{array}{l}\text { WHZ, z-score for weight-for-height; WAZ, z-score for weight-for-age; HAZ, z-score for height-for-age; } \\
\text { BAZ, z-score for BMI-for-age. }\end{array}$} \\
\hline \multicolumn{5}{|c|}{ a Average and standard deviation. Student $t$ test } \\
\hline b Number (percentage). chi- & & & & \\
\hline
\end{tabular}

\section{Discussion}


In this prospective preliminary study, we reported that $19.5 \%$ of mothers being vitamin D deficiency, and their neonates had a remarkably high prevalence of vitamin D deficiency at birth, with a rate of $78.5 \%$. We noticed very poor vitamin $D$ stores especially in twin neonates, even though all mothers took multivitamins (including vitamin D: 500 IU) daily during pregnancy.

Several studies conducted on singleton pregnancy among the Chinese population have investigated maternal $25[\mathrm{OH}] \mathrm{D}$ levels. Maternal vitamin D deficiency was reported in $79.2 \%$ of a multiethnic population without an investigation of prenatal vitamin D supplementation [34]. Approximately $10 \%$ of mothers took prenatal vitamin $D$, and the maternal vitamin $D$ deficiency rate was also high at $74.9 \%$. If the mothers took prenatal vitamin $D$ daily during the last one month before delivery or over three times per week, the maternal vitamin $D$ deficiency rates improved to $36.6 \%$ and $31.6 \%$, respectively [35]. The maternal vitamin $D$ deficiency rate in this study was lower than that in the aforementioned studies. This can be explained by the fact that all subjects in this study took vitamin $D$ supplements daily starting in the first trimester. Thus, we speculated that a high frequency of vitamin $D$ supplementation during pregnancy is an effective way to reduce the risk of maternal vitamin $D$ deficiency.

Previous studies have revealed that the rates of maternal and their neonatal vitamin $D$ deficiency are comparable in singleton pregnancy $[34,36]$. A similar statement was also found in the northern Indian twin pregnancies population, with a maternal vitamin D deficiency rate of $90 \%$ and neonatal vitamin $D$ deficiency rate of $89 \%$ [13]. However, the results of our study showed that the neonatal vitamin D deficiency rate was 4 -fold higher than the maternal vitamin $D$ deficiency rate, which was inconsistent with the aforementioned study. This is probably attributed to the distinct rates of maternal vitamin $D$ deficiency in the two studies. The significant difference in neonatal vitamin D deficiency and maternal vitamin $D$ deficiency rates in our study was likely due to the maternal vitamin $D$ supply to the two fetuses. In addition, we also found that the maternal vitamin $D$ level was an independent factor that correlated with the neonatal vitamin D level, which was consistent with previous studies [37].

The clinical practice guidelines of the Endocrinology Society recommend that pregnant women should take vitamin D supplements of at least $600 \mathrm{IU}$ daily. However, twin neonates were at a very high risk of vitamin D deficiency when twin pregnant women took vitamin D supplements of $500 \mathrm{IU}$ daily. Therefore, further investigations are needed to establish an appropriate dose that is effective for improving neonatal vitamin $\mathrm{D}$ deficiency and safe for the mothers' metabolism.

There are conflicting reports about the association between maternal vitamin $\mathrm{D}$ levels and neonatal birthweight in singleton pregnancy. Hossein Hajianfar et al found a significant inverse association between maternal vitamin D level and the rate of low birthweight neonates [38]; others have reported no relationship $[39,40]$. In our study, although the neonatal birthweight in the maternal vitamin $D$ deficiency group was lower than that in the other group, no correlation was found between maternal vitamin $D$ level and neonatal birthweight after adjusting for potential confounders. Interestingly, we found that the higher the maternal vitamin $\mathrm{D}$ level was, the smaller the discordance in birthweight between co-twins, thus 
presenting a negative association. However, further investigations are needed to detect the relative molecular mechanism.

Vitamin D deficiency in neonates has been shown to lead to a higher risk of food sensitivities in later life. In our study, because $99.3 \%$ of neonates were vitamin D deficient or insufficient, we compared the status of infants allergic to foods by maternal vitamin D levels. Although no significant difference was found among the maternal vitamin D deficiency, insufficiency and sufficiency groups in terms of allergies to foods, the allergy rate was highest in the maternal vitamin $D$ deficiency group. It is worth exploring whether maternal vitamin $D$ deficiency or neonatal vitamin $D$ deficiency predominantly influences infant allergies to foods.

The strength of our study is the specialized study population. We used strict inclusion and exclusion criteria to screen the participants. Monochorionic twin pregnant women were not selected due to the higher risks of maternal and fetal complications, higher rate of preterm birth and lower neonatal birthweight. Prepregnancy BMI also has an obvious impact on perinatal outcomes, so we only recruited women with prepregnancy BMls in the normal range. Additionally, the food sensitivities of infants at six months were followed, representing a relatively complete study design.

This preliminary study contributes new knowledge about the status of maternal and neonatal vitamin D levels in twin pregnancies, but several limitations of this study should be taken into consideration. First, compared with that of similar studies in singleton pregnancy, the sample size in this study is relatively small. Second, pregnant women in our hospital were routinely advised to take multivitamin supplements daily based on the clinical guidelines, particularly twin pregnant women; thus, there were no women who did not take multivitamin supplements as controls. Finally, singleton pregnant women taking the same multivitamin supplements and their neonates should be included as a control group. A large-scale study including singleton pregnancy and twin pregnancies and conducted in multiple centers is essential to better understand the prevalence of maternal and neonatal vitamin D deficiency in China among twin pregnancies populations.

\section{Conclusions}

In conclusion, this study suggested that despite of twin pregnant women taking prenatal vitamin $D$ supplements and the mothers' vitamin D deficiency partially improving, their twin neonates were at extremely high risk of vitamin D deficiency. These findings indicated that the obstetrician should give special attention to the dose of vitamin supplements provided to the twin pregnancy population.

\section{Abbreviations}

NC: Natural conception group; IVF: in vitro fertilization; BMI: Body mass index; Cl: Confidence interval; GA: Gestational age; GDM: Gestational diabetes mellitus; ICP: Intrahepatic cholestasis of pregnancy; LoTiS: Longitudinal Twin Study; OR: Odds ratio; PE: Preeclampsia; SGA: small for gestational age; ART: assisted 
reproductive technology; GHD: gestational hypertension disorder; WHZ: z-score for weight-for-height; WAZ: z-score for weight-for-age; HAZ: z-score for height-for-age; BAZ: z-score for BMI-for-age.

\section{Declarations}

\section{Acknowledgments}

The authors would like to thank all the participants, health professionals and researchers who contributed to this cohort study.

\section{Authors' contributions}

$\mathrm{CT}$ and $\mathrm{LW}$ designed the research protocol; $\mathrm{XL}$ and JXY conducted the study; $\mathrm{XL}$ and $\mathrm{JT}$ analyzed the data; $X L$ drafted the manuscript; $W L, C T, J Y Y, R S, M K, P B$ critically revised the manuscript; CT, QT, HQ provided funding resource. All authors have accepted responsibility for the entire content of this submitted manuscript and approved submission.

\section{Funding}

The National Key Research and Development Program of China (2018YFC1002900), National Natural Science Foundation of China (81520108013 and 81771613), Chongqing Science and Technology Commission (cstc2017jcyjBX0045), and NHC Key Laboratory of Birth Defects and Reproductive Health (2018-5). The founders played no role in the writing of the manuscript or the decision to submit it for publication.

\section{Availability of data and materials}

The LoTiS is being conducted mainly at the First Affiliated Hospital of Chongqing Medical University and Chongqing Women and Children's Health Center, where the staff are responsible for the collection, management, and distribution of data. All data are stored electronically in an anonymous format and are currently only available to LoTiS researchers. The datasets used and/or analyzed during the current study are available from the corresponding author upon request (chaotongcqmu@163.com).

\section{Ethics approval and consent to participate}

The experimental design and procedures were approved by the Ethics Committee of the First Affiliated Hospital of Chongqing Medical University (No. 201530).

\section{Consent for publication}

Not applicable.

\section{Competing interests}

The authors declare that they have no competing interests. 


\section{References}

1. Foger-Samwald U, Dovjak P, Azizi-Semrad U, Kerschan-Schindl K, Pietschmann P. Osteoporosis: Pathophysiology and therapeutic options. EXCLI J. 2020; 19:1017-1037.

2. Scheffer-Rath ME, Boot AM. The Many Facets of Vitamin D in the Pediatric Population. Pediatr Endocrinol Rev. 2020; 17:293-301.

3. Al Mheid I, Quyyumi AA. Vitamin D and Cardiovascular Disease: Controversy Unresolved. J Am Coll Cardiol. 2017; 70:89-100.

4. Hussain Gilani SY, Bibi S, Siddiqui A, Ali Shah SR, Akram F, Rehman MU. Obesity And Diabetes As Determinants Of Vitamin D Deficiency. J Ayub Med Coll Abbottabad. 2019; 31:432-435.

5. Khalil I, Barma P. Sub-continental Atmosphere and Inherent Immune System may have Impact on Novel Corona Virus' 2019 (nCovid-19) Prevalence in South East Asia. Mymensingh Med J. 2020; 29:473-480.

6. Courbebaisse M, Souberbielle JC, Baptiste A, Taieb J, Tsatsaris V, Guibourdenche J et al. Vitamin D status during pregnancy and in cord blood in a large prospective French cohort. Clin Nutr. 2019; 38:2136-2144.

7. Kohler M, Leiber F, Willems $H$, Merbold L, Liesegang A. Influence of altitude on vitamin $D$ and bone metabolism of lactating sheep and goats. J Anim Sci. 2013; 91:5259-5268.

8. Dinlen N, Zenciroglu A, Beken S, Dursun A, Dilli D, Okumus N. Association of vitamin D deficiency with acute lower respiratory tract infections in newborns. J Matern Fetal Neonatal Med. 2016; 29:928-932.

9. Cashman KD, Ritz C, Adebayo FA, Dowling KG, Itkonen ST, Ohman T et al. Differences in the dietary requirement for vitamin $\mathrm{D}$ among Caucasian and East African women at Northern latitude. Eur $\mathrm{J}$ Nutr. 2019; 58:2281-2291.

10. Petrenya N, Lamberg-Allardt C, Melhus M, Broderstad AR, Brustad M. Vitamin D status in a multiethnic population of northern Norway: the SAMINOR 2 Clinical Survey. Public Health Nutr. 2020; 23:1186-1200.

11. Elsori DH, Hammoud MS. Vitamin D deficiency in mothers, neonates and children. J Steroid Biochem Mol Biol. 2018; 175:195-199.

12. Esmeraldo CUP, Martins MEP, Maia ER, Leite JLA, Ramos JLS, Goncalves J, Jr. et al. Vitamin D in Term Newborns: Relation with Maternal Concentrations and Birth Weight. Ann Nutr Metab. 2019; 75:39-46.

13. Goswami D, Rani R, Saxena A, Arora MS, Batra S, Sreenivas V. Maternal and neonatal vitamin-D status in twin versus singleton pregnancies. J Obstet Gynaecol Res. 2016; 42:1250-1257.

14. Yoon HK. Gestational Diabetes Mellitus, Fetal Growth and Vitamin D. J Bone Metab. 2017; 24:155159.

15. Vijay A, Sinha S, Sindgikar SP, Shenoy VD. Effect of gestational diabetes on the vitamin D levels in the neonates: a case control study. Turk J Pediatr. 2020; 62:431-435. 
16. Curtis EM, Moon RJ, Harvey NC, Cooper C. Maternal vitamin D supplementation during pregnancy. $\mathrm{Br}$ Med Bull. 2018; 126:57-77.

17. Perezabad L, Lopez-Abente J, Alonso-Lebrero E, Seoane E, Pion M, Correa-Rocha R. The establishment of cow's milk protein allergy in infants is related with a deficit of regulatory $T$ cells (Treg) and vitamin D. Pediatr Res. 2017; 81:722-730.

18. Kechichian E, Ezzedine K. Vitamin D and the Skin: An Update for Dermatologists. Am J Clin Dermatol. 2018; 19:223-235.

19. Sablok A, Batra A, Thariani K, Batra A, Bharti R, Aggarwal AR et al. Supplementation of vitamin D in pregnancy and its correlation with feto-maternal outcome. Clin Endocrinol (Oxf). 2015; 83:536-541.

20. Sotunde OF, Laliberte A, Weiler HA. Maternal risk factors and newborn infant vitamin D status: a scoping literature review. Nutr Res. 2019; 63:1-20.

21. Fernando S, Kumar S, Bakr M, Speicher D, Lea R, Scuffham PA et al. Children's untreated decay is positively associated with past caries experience and with current salivary loads of mutans Streptococci; negatively with self-reported maternal iron supplements during pregnancy: a multifactorial analysis. J Public Health Dent. 2019; 79:109-115.

22. Saraf R, Morton SM, Camargo CA, Jr., Grant CC. Global summary of maternal and newborn vitamin $D$ status - a systematic review. Matern Child Nutr. 2016; 12:647-668.

23. Stagi S, Rigante D. Vitamin D and juvenile systemic lupus erythematosus: Lights, shadows and still unresolved issues. Autoimmun Rev. 2018; 17:290-300.

24. Martin JA, Hamilton BE, Osterman MJK, Driscoll AK. Births: Final Data for 2018. Natl Vital Stat Rep. 2019; 68:1-47.

25. Martin JA, Hamilton BE, Ventura SJ, Osterman MJ, Wilson EC, Mathews TJ. Births: final data for 2010. Natl Vital Stat Rep. 2012; 61:1-72.

26. Ventura SJ, Martin JA, Curtin SC, Mathews TJ. Births: final data for 1997. Natl Vital Stat Rep. 1999; 47:1-96.

27. Chang YL, Wang TH, Abufraijeh SM, Chang SD, Chao AS, Hsieh PCC. Preliminary report of altered insulin secretion pattern in monochorionic twin pregnancies complicated with selective intrauterine growth restriction. Taiwan J Obstet Gynecol. 2017; 56:51-54.

28. Mihaela B, Radu V, Anca B, Alexandra M, loana C, Simona V. Monochorionic vs Dichorionic Twins: Kanet Test vs Postnatal Neurodevelopment. Maedica (Buchar). 2020; 15:61-70.

29. Matsuda N, Taki A, Tsuji A, Nakajima K, Takasawa K, Morioka C et al. Perinatal factors affecting growth and development at age 3 years in extremely low birth weight infants born small for gestational age. Clin Pediatr Endocrinol. 2018; 27:31-38.

30. Mathew EM, Moorkoth S, Rane PD, Lewis L, Rao P. Cost-Effective HPLC-UV Method for Quantification of Vitamin D2 and D3 in Dried Blood Spot: A Potential Adjunct to Newborn Screening for Prophylaxis of Intractable Paediatric Seizures. Chem Pharm Bull (Tokyo). 2019; 67:88-95. 
31. Kovacs CS. Vitamin D in pregnancy and lactation: maternal, fetal, and neonatal outcomes from human and animal studies. Am J Clin Nutr. 2008; 88:520S-528S.

32. Traglia M, Windham GC, Pearl M, Poon V, Eyles D, Jones KL et al. Genetic Contributions to Maternal and Neonatal Vitamin D Levels. Genetics. 2020; 214:1091-1102.

33. Wei $F$, Wang $Z$, Wang J, Xu H, Zhou H. Serum vitamin D levels among children aged 0-12 years in the First Affiliated Hospital of Harbin Medical University, China. J Public Health (Oxf). 2018; 40:721-726.

34. Wang Y, Li H, Zheng M, Wu Y, Zeng T, Fu J et al. Maternal vitamin D deficiency increases the risk of adverse neonatal outcomes in the Chinese population: A prospective cohort study. PLoS One. 2018; 13:e0195700.

35. Zhu T, Liu TJ, Ge X, Kong J, Zhang LJ, Zhao Q. High prevalence of maternal vitamin D deficiency in preterm births in northeast China, Shenyang. Int J Clin Exp Pathol. 2015; 8:1459-1465.

36. Windham GC, Pearl M, Anderson MC, Poon V, Eyles D, Jones KL et al. Newborn vitamin D levels in relation to autism spectrum disorders and intellectual disability: A case-control study in california. Autism Res. 2019; 12:989-998.

37. Ariyawatkul K, Lersbuasin P. Prevalence of vitamin D deficiency in cord blood of newborns and the association with maternal vitamin D status. Eur J Pediatr. 2018; 177:1541-1545.

38. Yu X, Wang W, Wei Z, Ouyang F, Huang L, Wang X et al. Vitamin D status and related factors in newborns in Shanghai, China. Nutrients. 2014; 6:5600-5610.

39. Shor DB, Barzel J, Tauber E, Amital H. The effects of maternal vitamin D on neonatal growth parameters. Eur J Pediatr. 2015; 174:1169-1174.

40. Yun C, Chen J, He Y, Mao D, Wang R, Zhang Y et al. Vitamin D deficiency prevalence and risk factors among pregnant Chinese women. Public Health Nutr. 2017; 20:1746-1754.

\section{Figures}




\section{Dichorionic twin pregnancies from LoTiS$$
\mathrm{n}=190
$$

3 women chronic metabolic diseases

44 women with $\mathrm{BMI} \geq 24.0$

21 women with $\mathrm{BMI}<18.5$

5 women without routine usage of vitamin D

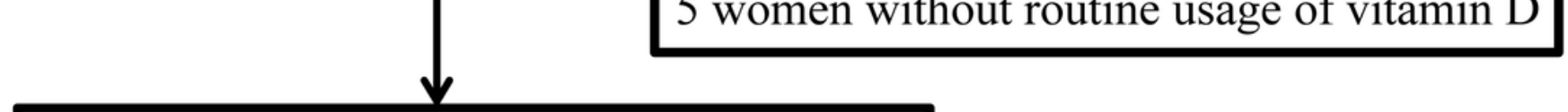

Eligible dichorionic twin pregnancies

$$
\mathrm{n}=117
$$

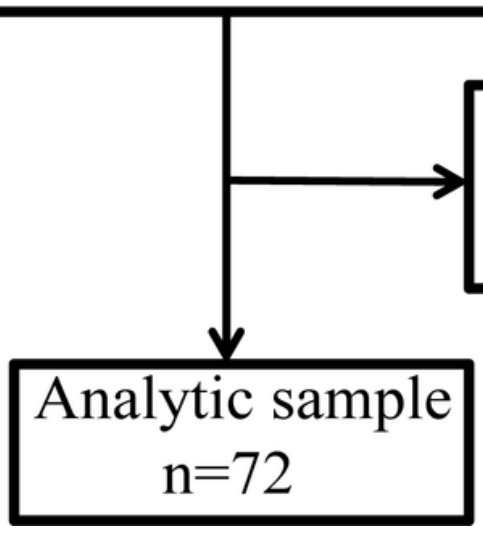

25 either mother or neonates without blood sample

3 either twin neonates with birth weight $<1500 \mathrm{~g}$

17 twin intants without postnatal follow-up

Figure 1

The selection process for this study.

A Correlation of maternal and neonatal 25[OH]D levels
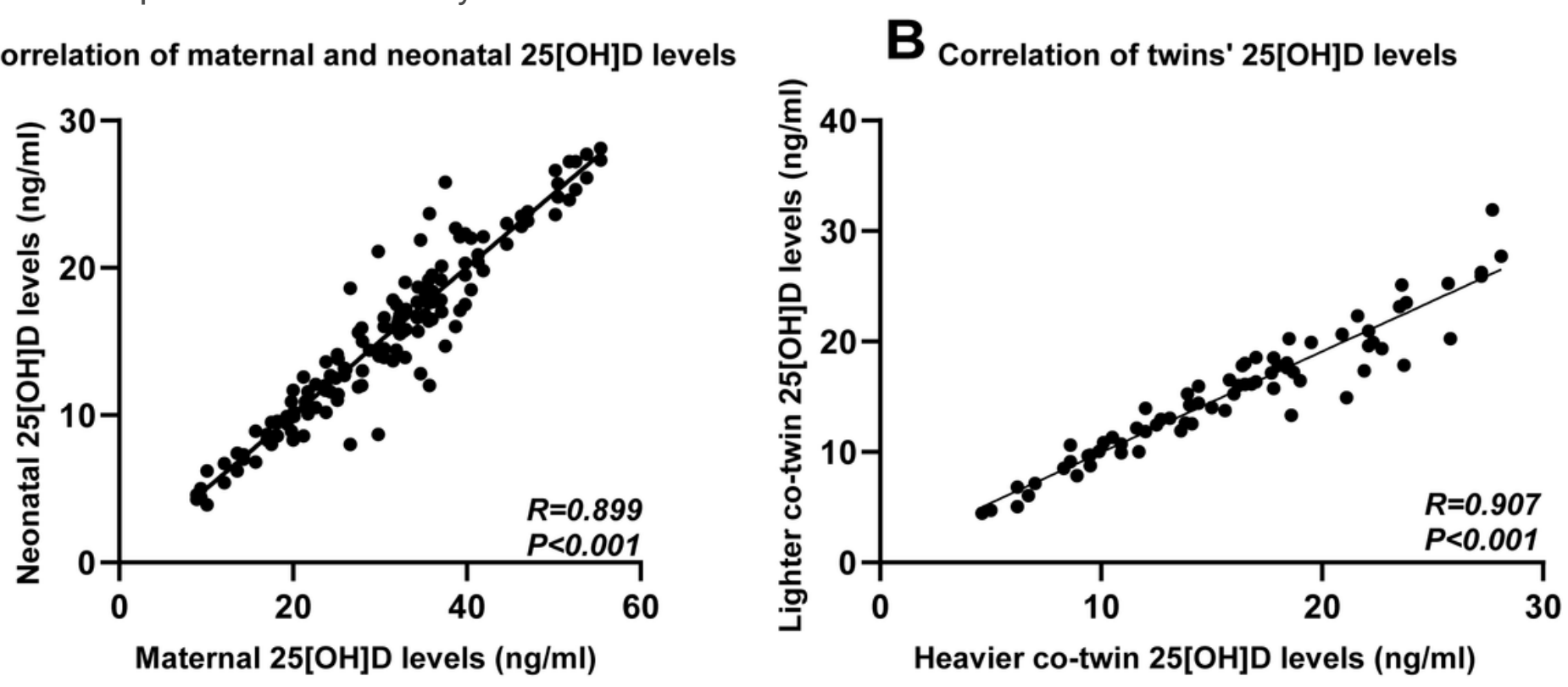

Figure 2 
Correlation between maternal and neonatal 25[OH]D levels and correlation of co-twins' 25[OH]D levels. A) There was a directly proportional correlation between maternal 25[OH]D levels and neonatal 25[OH]D levels $(r=0.90, p<0.001)$; B)A significantly positive correlation was found between co-twins in terms of neonatal 25[OH]D level $(r=0.91, p<0.001)$.

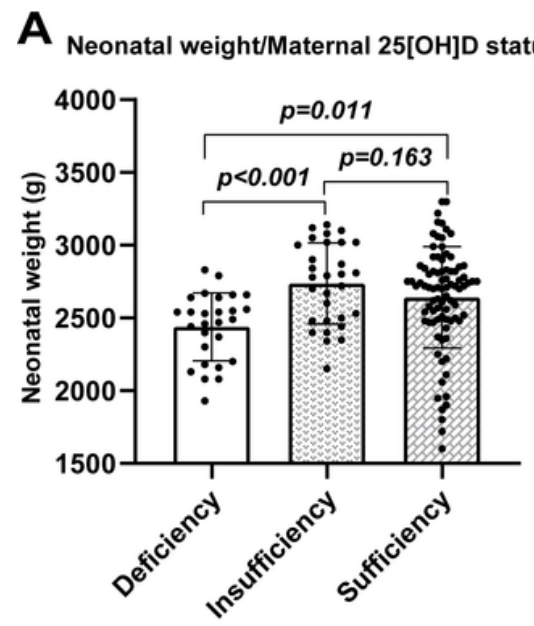

Maternal 25[OH]D status
B

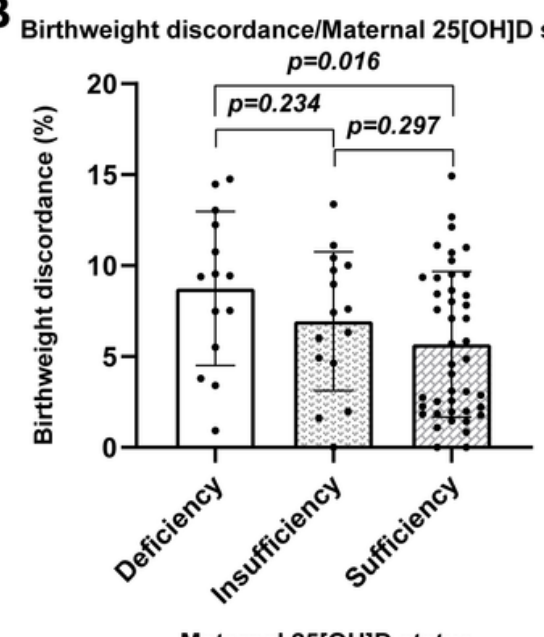

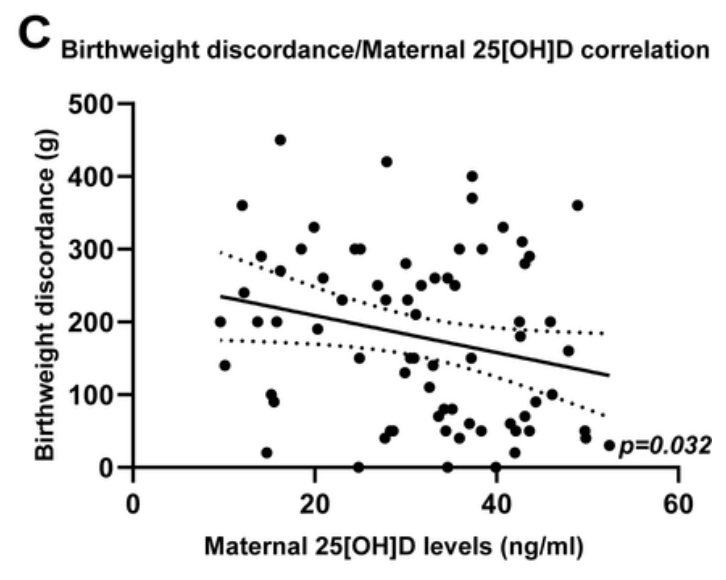

\section{Figure 3}

The impact of maternal 25[OH]D levels on neonatal birthweight. A)The neonatal birthweight was significantly different between the maternal 25[OH]D status(deficiency group vs insufficiency group, $\mathrm{P}<0.001$; deficiency group vs sufficiency group, $\mathrm{P}=0.011)$; $\mathrm{B})$ The neonatal birthweight discordance $(\%)$ was significantly different between the maternal 25[OH]D status(deficiency group vs sufficiency group, $\mathrm{P}=0.016) ; \mathrm{C}$ ) Maternal 25[OH]D levels were negatively correlated with the discordance in birthweight between co-twins, with the discordance in birthweight between co-twins decreased $2.67 \%$ when maternal 25[OH]D level increased by $1 \mathrm{ng} / \mathrm{mL}(95 \% \mathrm{Cl}:-5.11,-0.23 . \mathrm{p}=0.032)$.

\section{Supplementary Files}

This is a list of supplementary files associated with this preprint. Click to download.

- SupplementaryFile1.docx

- SupplementaryFile2.docx 